\title{
Fractures modeling in system of engineering analysis
}

\author{
A.Yu. Babin \\ FSBEI HE «Ufa State Petroleum Technological \\ University», Ufa, Russia \\ aubabin@yandex.ru
}

\author{
V.A. Gafarova \\ FSBEI HE «Ufa State Petroleum Technological \\ University», Ufa, Russia \\ gafarova.vika@bk.ru
}

\author{
V.K. Berdin \\ FSBEI HE «Ufa State Petroleum Technological \\ University», Ufa, Russia \\ berdinvk@mail.ru
}

\begin{abstract}
Equipment used at the enterprises implementing oil and gas technologies is potentially hazardous and should be of high degree of reliability. Reliability of equipment reduces the number of defects appearing during the operation process. One of hazardous and unpredictable defects is fracture. If there is a fracture, it is permitted to operate an installation under operating conditions up to the definite critical size of the fracture. However, to operate the installation with fracture, it is required to perform a detailed study of the defect and to calculate residual operation life of the equipment. One of the most suitable methods of fracture studying is finite element analysis. The article presents the method of fractures modeling in the system of engineering analysis, ANSYS, and comparison of obtained results with analytical solution.
\end{abstract}

Keywords-oil refineries, oil and gas technologies, defect, fracture, modeling, system of engineering analysis, stress intensity factor.

\section{INTRODUCTION}

Equipment implementing oil and gas technologies operates under conditions of thermal force impact, cycling loads, instability of operating parameters. Taking into account that this equipment have large dimensions, it could be noted that a great number of fire and explosion hazard and toxic substances are in a limiting state per unit time [1].

Equipment reliability reduces the number of defects appearing during the operation process. One of the hazardous and unpredictable defects is fracture. For certain types of equipment, operation under operating conditions up to the definite critical size of the fracture is acceptable [2].

It should be noted that provision of equipment safety is based on the concept of destruction control, which lies in the fact that defects are always present, even in new structures [3].

\section{MAIN PART}

Possibility of operating equipment with fractures comes from the availability of critical size of fractures, up to the achievement of which the fractures is in latent state. In order to determine critical fracture length (a), it is necessary to know the value of stress intensity factor $\mathrm{K}=\left(\mathrm{N} / \mathrm{m}^{3 / 2}\right)[4]$ :

$$
\mathrm{K}_{\mathrm{I}}=\sigma \sqrt{\pi \mathrm{a}},
$$

where $\sigma$ - critical mechanical stress, MPa.

Destruction occurs when stress in the construction material with fracture of the length (a) reaches critical value $\sigma_{\text {cr. }}$ In such case:

$$
\mathrm{K}_{\mathrm{I}}=\sigma_{\mathrm{cr}} \sqrt{\pi \mathrm{a}}=\mathrm{K}_{\mathrm{c}}
$$

being $\mathrm{K}_{\mathrm{c}}$ - characteristic of the material.

When detecting fracture by means of nondestructive control performance or visual examination of the equipment, it is necessary to assess the critical size of defects and make decision regarding the possibility of its further operation [3].

When making such decision, it is necessary to take into account possible change of $\mathrm{K}_{\mathrm{c}}$ value in the process of damages accumulation. In his paper, Kuzeev M.I. shows that in case of fatigue loading of steel samples in the low-cycle area as per the pure bending scheme, under the general tendency for the $\mathrm{K}_{\mathrm{c}}$ decrease, extreme values are observed when achieving 30 $\%$ and $70 \%$ of the number of cycles to the complete failure.

These results point to the high-risk level when operating equipment with fractures. Reduction of the risk level is possible by filling the fracture cavity with the composition material consisting of various fillers by means of using special device [5].

Multivariance of change in construction material characteristics during the operation process, the type of 
interaction with the composition material requires performance of multiple calculations to assess fracture behavior in the construction. Such task could be fulfilled by means of carrying out studies on three-dimensional models by the finite elements method (FEM) [6].

Software package ANSYS was used for this purpose. At the first stage of studies, the flat plate with edge throughfracture of 1 length was simulated (figure 1).

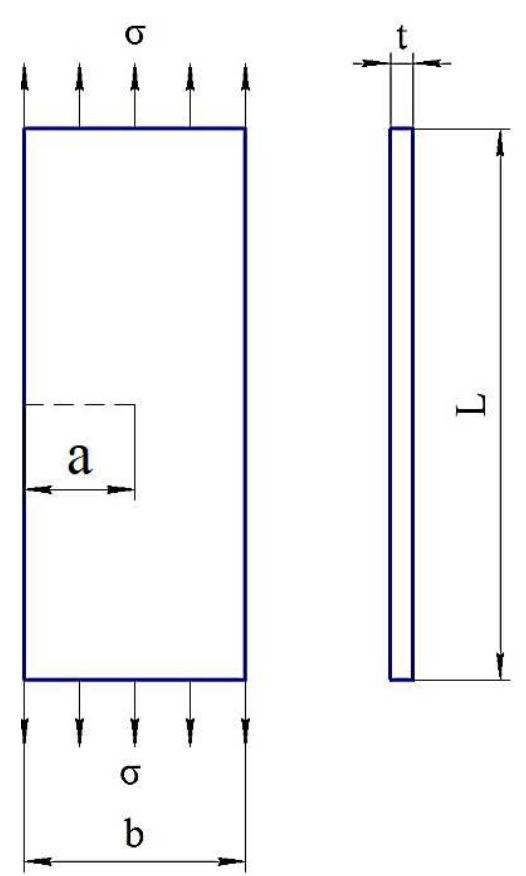

Fig. 1. Flat plate with edge through-fracture

Fracture modeling in the system of engineering analysis ANSYS is performed by means of the eXtended Finite Element Method (hereinafter referred to as the XFEM). This method proposes a suitable engineering approach for fractures modeling, not involving FE mesh reconstruction in the field of fracture development. The method of fractures modeling based on XFEM also can be applied for fatigue fractures growth modeling [7].

Fracture modeling in MAPDL is more suitable to perform by entering the required commands in the command line. The whole process of modeling could be divided into two stages listed in table 1.
TABLE I. PROCEDURE OF FRACTURE MODELING IN MAPDL

\begin{tabular}{|c|c|}
\hline Stage of modeling & Command \\
\hline Selection of the FE type & Et; keyopt \\
\hline $\begin{array}{c}\text { Determination of material } \\
\text { properties }\end{array}$ & mp, ex (E); mp, nuxy $(\mu) ; m p$, dens $(\rho)$ \\
\hline $\begin{array}{c}\text { Creation of points in the selected } \\
\text { system of coordinates }\end{array}$ & K \\
\hline $\begin{array}{l}\text { Determination of the field of } \\
\text { elements (figure 2) }\end{array}$ & A \\
\hline Determination of FE size & $\begin{array}{c}\text { Lsel; lesize } \\
\text { (line division to FE) }\end{array}$ \\
\hline Creation of FE mesh (figure 3) & Esize (FE size); amesh \\
\hline Uniting FE into group & $\mathrm{Cm}$ \\
\hline $\begin{array}{l}\text { Determination of FE which will } \\
\text { take part in XFEM method }\end{array}$ & Xfenrich \\
\hline Fracture placement (figure 3 ) & Xfdata \\
\hline Provision of boundary conditions & Press (pressure); d (joint constraint) \\
\hline $\begin{array}{l}\text { Determination of the solution } \\
\text { parameters }\end{array}$ & Cint \\
\hline Displaying of the solution results & Prcint \\
\hline
\end{tabular}

The ANSYS system does not use some definite measuring system, that is why, entered data should be comparable (table 2) [7].

TABLE II. SELECTED MEASURING UNITS

\begin{tabular}{|c|c|}
\hline Parameter & Measuring unit \\
\hline Length & $\mathrm{mm}$, millimeter \\
\hline Power & $\mathrm{N}$, Newton \\
\hline Weight & $\mathrm{t}$, tonne \\
\hline Time & $\mathrm{s}$, second \\
\hline Mechanical stress & $\mathrm{MPa}\left(\mathrm{N} / \mathrm{mm}^{2}\right)$ \\
\hline Density & $\mathrm{t} / \mathrm{mm}^{2}$ \\
\hline
\end{tabular}

Sample geometrical dimensions and testing parameters are provided in table 3 .

TABLE III. SAMPLE GEOMETRICAL DIMENSIONS AND TESTING PARAMETERS

\begin{tabular}{|l|c|c|c|c|c|}
\hline \multirow{3}{*}{ Parameter } & $\begin{array}{c}\text { Fracture } \\
\text { length, mm }\end{array}$ & \multicolumn{3}{|c|}{$\begin{array}{c}\text { Sample } \\
\text { geometry, mm }\end{array}$} & Tensile stress, MPa \\
\cline { 2 - 6 } & $\boldsymbol{a}$ & $\boldsymbol{b}$ & $\boldsymbol{h}$ & $\boldsymbol{t}$ & $\boldsymbol{\sigma}$ \\
\hline Value & 20 & 40 & 200 & 4 & 100 \\
\hline
\end{tabular}

Material properties are specified for steel 09G2S:

- density $\rho=7.85 \cdot 10^{-9} \mathrm{t} / \mathrm{mm}^{3}\left(7850 \mathrm{~kg} / \mathrm{m}^{3}\right)$;

- module of elasticity $\mathrm{E}=2 \cdot 10^{5} \mathrm{MPa}$;

- Poisson ratio $\mu=0.3$.

Let us complete the set task in the following schemes of the stressed-deformed state:

- 2D, the plain deformation state (hereinafter referred to as the PDS) in Mechanical APDL (hereinafter MAPDL);

- 2D, plain stress state (hereinafter PSS) in MAPDL;

- 3D in ANSYS Workbench (hereinafter WB). 
The fracture model developed in MAPDL is presented in figures 2,3 .

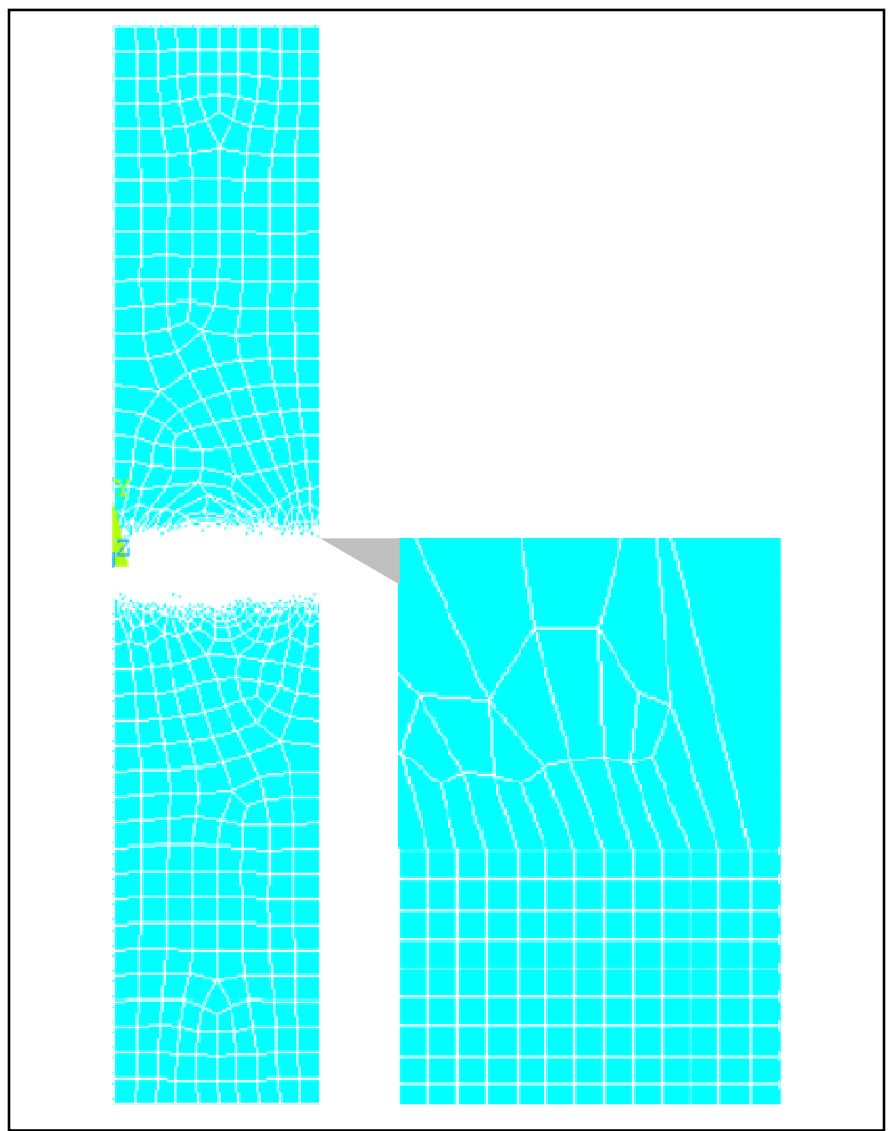

Fig. 2. FE mesh

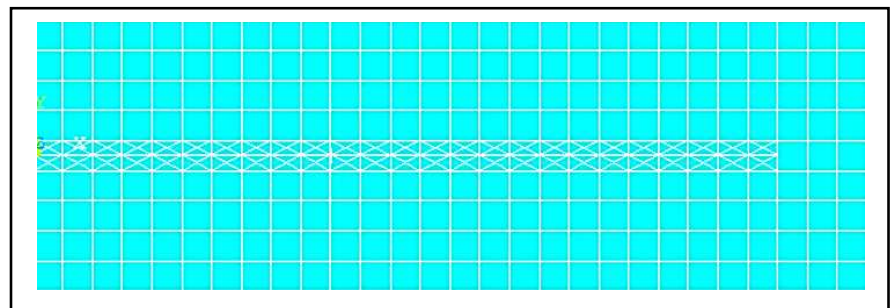

Fig. 3. Fracture simulated by XFEM method

ANSYS Workbench by means of commands in Fracture inset prevents through fracture modeling. That is why, it was decided to artificially implement in the plate the fracture of such geometry, angle between the edges, at the apex of which it will not depend on the fracture depth (figure 4).

Distribution of equivalent stresses obtained in Mechanical APDL and ANSYS Workbench at the apex of fracture is illustrated in figure 5 .

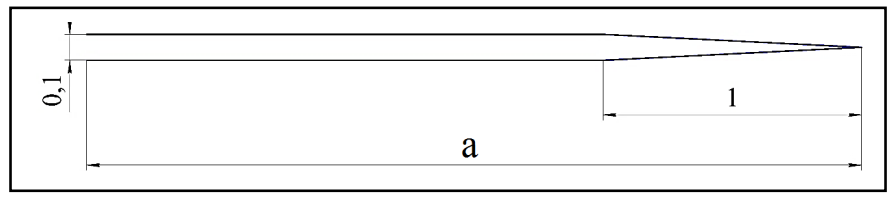

Fig. 4. Fracture dimensions
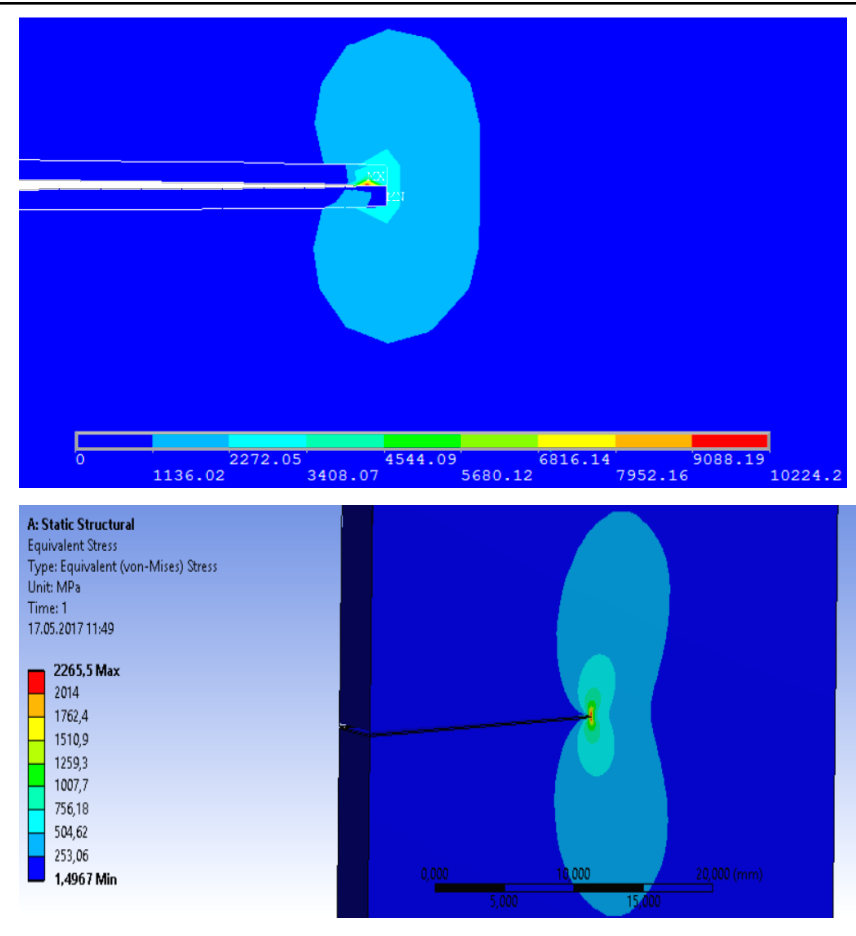

Fig. 5. Diagram of equivalent stresses distribution, $\mathrm{MPa}$

Moreover, ANSYS Workbench allows displaying the calculation result of the $K_{\mathrm{I}}$ factor along the fracture length (figure 6).

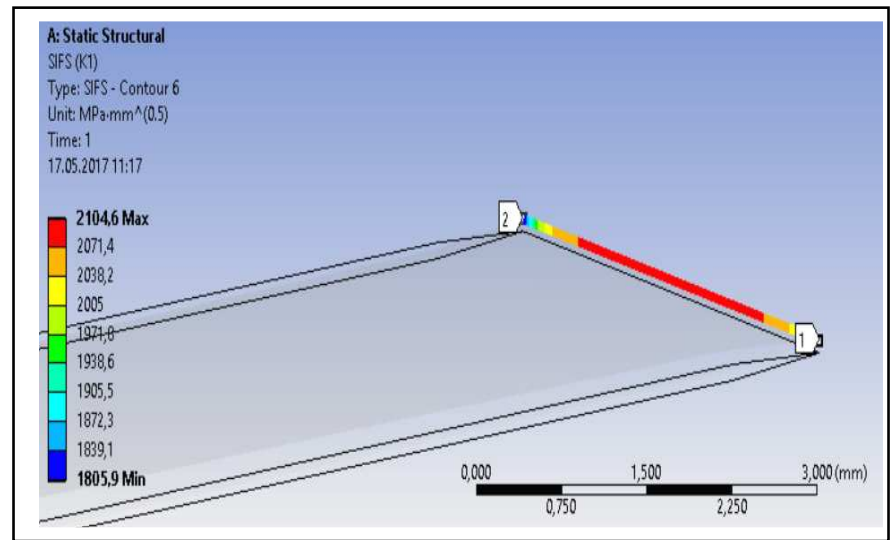

Fig. 6. Diagram of $\mathrm{K}_{\mathrm{I}}$ distribution on fracture front, $\mathrm{MPa} \cdot \mathrm{mm}^{0.5}$ 
To determine dependence of fracture length a and stress intensity factor $K_{I}$ for the I-st type of loading [8], the process of extension of the flat plate with through-fracture of the length $1 \leq \mathrm{a} \leq 39 \mathrm{~mm}$ was simulated.

To assess results of fracture modeling, it was decided to compare results of $\mathrm{K}_{\mathrm{I}}$ calculation, obtained in ANSYS, with the results, obtained from the analytical method. Let us analytically solve the task by using formulas specified in GOST 25.506-85 [9] (hereinafter GOST) and in the reference book [10].

In accordance with GOST for the flat plate with edge through-fracture, $K_{\mathrm{I}}$ in a wide range of fracture lengths $(0 \leq \lambda$ $\leq 0.6$ ), bing $\lambda=\mathrm{a} / \mathrm{b}$, is calculated by the formula:

$$
\mathrm{K}_{\mathrm{I}}=\frac{\mathrm{P} \sqrt{\mathrm{a}}}{\mathrm{t} \cdot \mathrm{b}} \mathrm{Y}_{5} \text {, }
$$

where, $Y_{5}=1.99-0.41 \frac{1}{b}+18.7\left(\frac{1}{b}\right)^{2}-38.48\left(\frac{1}{b}\right)^{3}+53.85\left(\frac{1}{b}\right)^{4}$.

In accordance with the reference book [10], $\mathrm{K}_{\mathrm{I}}$ under condition of $0 \leq \lambda \leq 0.6$ is calculated by the formula:

$$
\mathrm{K}_{\mathrm{I}}=\sigma \sqrt{\pi \mathrm{a}} \cdot \mathrm{F}_{\mathrm{I}}(\lambda),
$$

where, $\mathrm{F}_{\mathrm{I}}(\lambda)=1.12-0.231 \lambda+10.55(\lambda)^{2}-21.72(\lambda)^{3}+30.39(\lambda)^{4}$

In order to verify, let us compare results of $\mathrm{K}_{\mathrm{I}}$, obtained in ANSYS, with the results, calculated by analytical method (table 4). Graphic representation of the results is provided in figure 7.

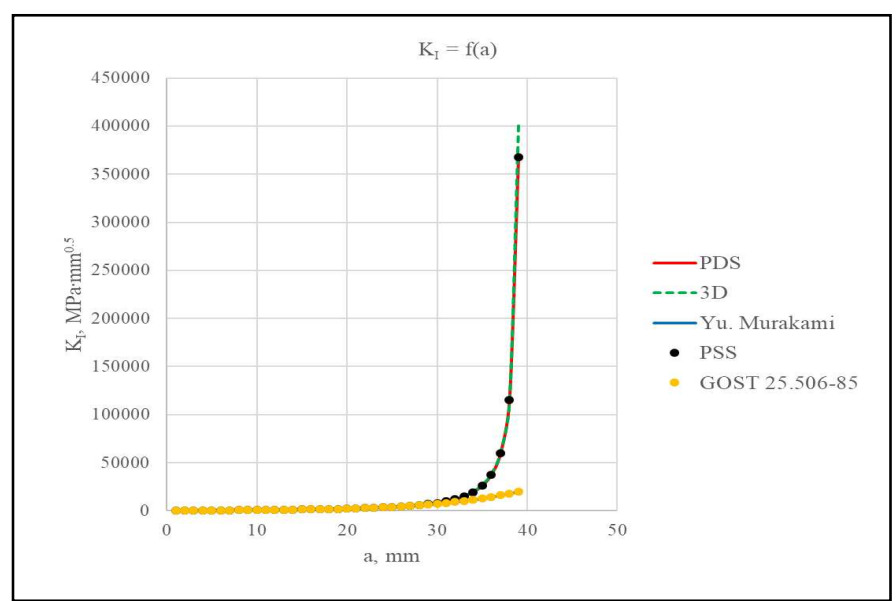

Fig. 7. Comparison of results obtained by all mentioned methods

The graph shows that good repeatability of $\mathrm{K}_{\mathrm{I}}$ values is observed within the interval of fracture lengths from 0 up to $24 \mathrm{~mm}$, which makes $60 \%$ of the total width of the sample. Thereafter values obtained in ANSYS and results of analytical method differ.

Let us determine the function which provides the most precise $K_{I}=f(a)$ dependence. Analyzing the obtained results, it was found out that $K_{I}=f(a)$ dependence is unstable in the fracture lengths range. The most monotonic behavior is observed within the intervals $0 \leq \lambda \leq 60 \%$ and $60 \% \leq \lambda \leq 100 \%$.

The interval of $\mathrm{K}_{\mathrm{I}}=\mathrm{f}(\mathrm{a})$ dependence in case of $0 \leq \lambda \leq 60 \%$ is most accurately described by the third-order polynom (figure 8 ):

$$
K_{I}=y_{0}+b \cdot a+c \cdot a^{2}+d \cdot a^{3},
$$

where $\mathrm{y}_{0}=81.7874$;

$$
\begin{aligned}
& b=108.5224 ; \\
& c=-6.7414 ; \\
& d=0.3382 .
\end{aligned}
$$

\begin{tabular}{|c|c|c|c|c|c|}
\hline \multirow[b]{2}{*}{$\mathbf{l}, \mathbf{m m}$} & \multicolumn{5}{|c|}{$\mathrm{K}_{\mathrm{I}}, \mathbf{M P a} \cdot \mathbf{m m}^{2}$} \\
\hline & $\begin{array}{c}\text { GOST } \\
25.506-85\end{array}$ & $\begin{array}{c}\text { Yu. } \\
\text { Murakami }\end{array}$ & PDS & PSS & $3 D$ \\
\hline 1 & 199.1 & 198.6 & 200.1 & 200.1 & 193.9 \\
\hline 2 & 284.5 & 283.8 & 285.3 & 285.1 & 293.6 \\
\hline 3 & 355.1 & 354.1 & 354.7 & 354.1 & 368.1 \\
\hline 4 & 420.6 & 419.5 & 419.1 & 417.9 & 436.1 \\
\hline 5 & 485.0 & $\begin{array}{l}483.8 \\
\end{array}$ & 482.1 & 480.4 & 501.4 \\
\hline 6 & 550.3 & 549.0 & 546.3 & 544.1 & 569.7 \\
\hline 7 & 617.8 & 616.4 & 612.3 & 609.5 & 639.1 \\
\hline 8 & 688.5 & 687.0 & 681.5 & 678.4 & 712.0 \\
\hline 9 & 763.2 & 761.6 & 755.1 & 751.5 & 789.6 \\
\hline 10 & 842.9 & 841.1 & 833.9 & 830.2 & 872.9 \\
\hline 11 & 928.4 & 926.5 & 920.1 & 916.5 & 962.6 \\
\hline 12 & 1020.9 & 1018.9 & 1014.7 & 1011.4 & 1060.5 \\
\hline 13 & 1122.0 & 1119.8 & 1120.1 & 1117.0 & 1167.8 \\
\hline 14 & 1233.1 & 1230.8 & 1224.7 & 1222.1 & 1285.0 \\
\hline 15 & 1356.2 & 1353.8 & 1349.1 & 1346.9 & 1415.4 \\
\hline 16 & 1493.5 & 1491.0 & 1487.4 & 1485.1 & 1559.8 \\
\hline 17 & 1647.7 & 1645.0 & 1641.8 & 1638.8 & 1720.6 \\
\hline 18 & 1821.8 & 1818.9 & $\begin{array}{l}1817.0 \\
\end{array}$ & 1813.0 & 1901.2 \\
\hline 19 & 2018.9 & 2015.9 & 2013.2 & 2008.1 & 2104.6 \\
\hline 20 & 2243.1 & 2239.8 & 2237.9 & 2231.9 & 2335.2 \\
\hline 21 & 2498.3 & 2494.8 & 2493.2 & 2486.3 & 2598.6 \\
\hline 22 & 2789.3 & 2785.6 & 2786.1 & 2778.7 & 2899.9 \\
\hline 23 & 3121.1 & 3117.2 & 3123.6 & 3116.0 & 3249.2 \\
\hline 24 & 3499.5 & 3495.3 & 3521.1 & 3513.4 & 3656.7 \\
\hline 25 & 3930.4 & 3926.0 & 3994.5 & 3987.2 & 4128.2 \\
\hline 26 & 4420.5 & 4415.8 & 4565.6 & 4558.2 & 4705.9 \\
\hline
\end{tabular}

TABLE IV. $\quad \mathrm{K}_{\mathrm{I}}$ VALUES OBTAINED BY ANALYTICAL METHOD AND IN ANSYS SYSTEM 


\begin{tabular}{|l|l|l|l|l|l|}
\hline 27 & 4976.9 & 4971.9 & 5172.8 & 5165.8 & 5392.1 \\
\hline 28 & 5607.3 & 5602.0 & 5976.1 & 5971.1 & 6230.9 \\
\hline 29 & 6319.9 & 6314.3 & 6971.4 & 6966.9 & 7270.8 \\
\hline 30 & 7123.7 & 7117.7 & 8221.6 & 8214.4 & 8585.9 \\
\hline 31 & 8027.9 & 8021.6 & 9857.6 & 9847.3 & 10286.0 \\
\hline 32 & 9042.6 & 9035.9 & 12047.0 & 12034.0 & 12549.0 \\
\hline 33 & 10178.4 & 10171.3 & 15087.0 & 15071.0 & 15667.0 \\
\hline 34 & 11446.6 & 11439.1 & 19480. & 19462.0 & 20169.0 \\
\hline 35 & 12859.0 & 12851.1 & 26268.0 & 26245.0 & 27076.0 \\
\hline 36 & 14428.2 & 14419.8 & 37654.0 & 37624.0 & 38605.0 \\
\hline 37 & 16167.4 & 16158.5 & 59659.0 & 59613.0 & 60537.0 \\
\hline 38 & 18090.5 & 18081.0 & 115220.0 & 115120.0 & 112830.0 \\
\hline 39 & 20211.9 & 20201.9 & 367690.0 & 367910.0 & 402090.0 \\
\hline
\end{tabular}



Fig. 8. Comparison of results obtained in MAPDL and by means of function in interval of $0 \leq \lambda \leq 60 \%$

The interval of $\mathrm{K}_{\mathrm{I}}=\mathrm{f}(\mathrm{a})$ dependence in case of $60 \% \leq \lambda \leq 100 \%$ is most accurately described by the exponential function (figure 9):

$$
\mathrm{K}_{\mathrm{I}}=\mathrm{y}_{0}+\mathrm{b} \cdot \mathrm{e}^{\mathrm{c} \cdot \mathrm{a}}+\mathrm{d} \cdot \mathrm{e}^{\mathrm{g} \cdot \mathrm{a}},
$$

where $\mathrm{y}_{0}=3920.1834$;

$$
\begin{aligned}
& \mathrm{a}=0.0634 ; \\
& \mathrm{b}=0.3658 ; \\
& \mathrm{c}=3.3678 \cdot 10^{-26} ; \\
& \mathrm{d}=1.8241 .
\end{aligned}
$$

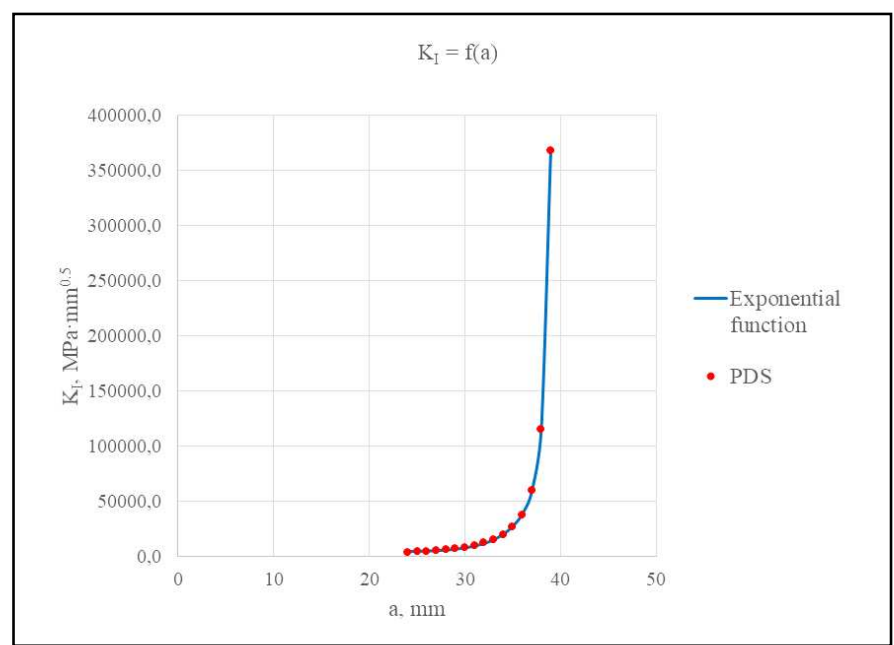

Fig. 9. Comparison of results obtained in MAPDL and by means of function in interval of $60 \leq \lambda \leq 100 \%$

During the next stage of study, 09G2S steel samples with a fracture were destructed on the static and cyclic tests unit Instron 8801. Samples before and after destruction are shown in Figures 10, 11.

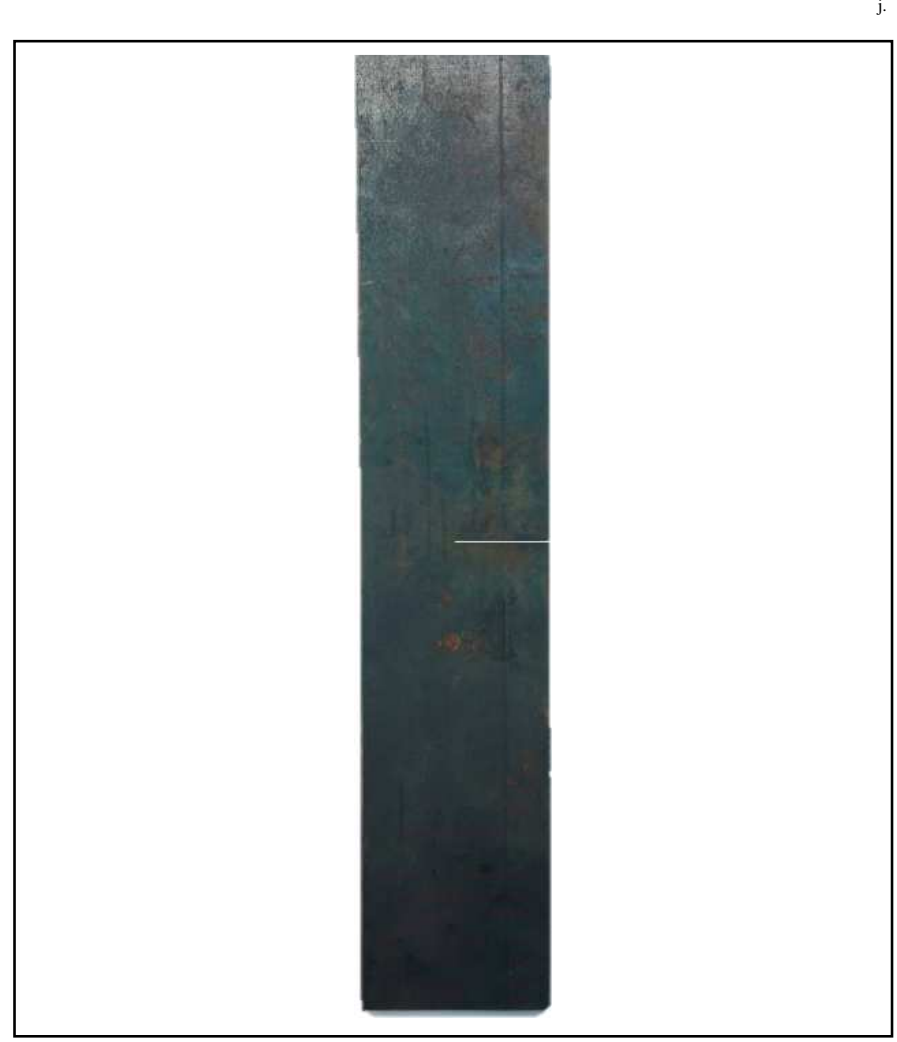

Fig. 10. 09G2S steel sample before destruction 


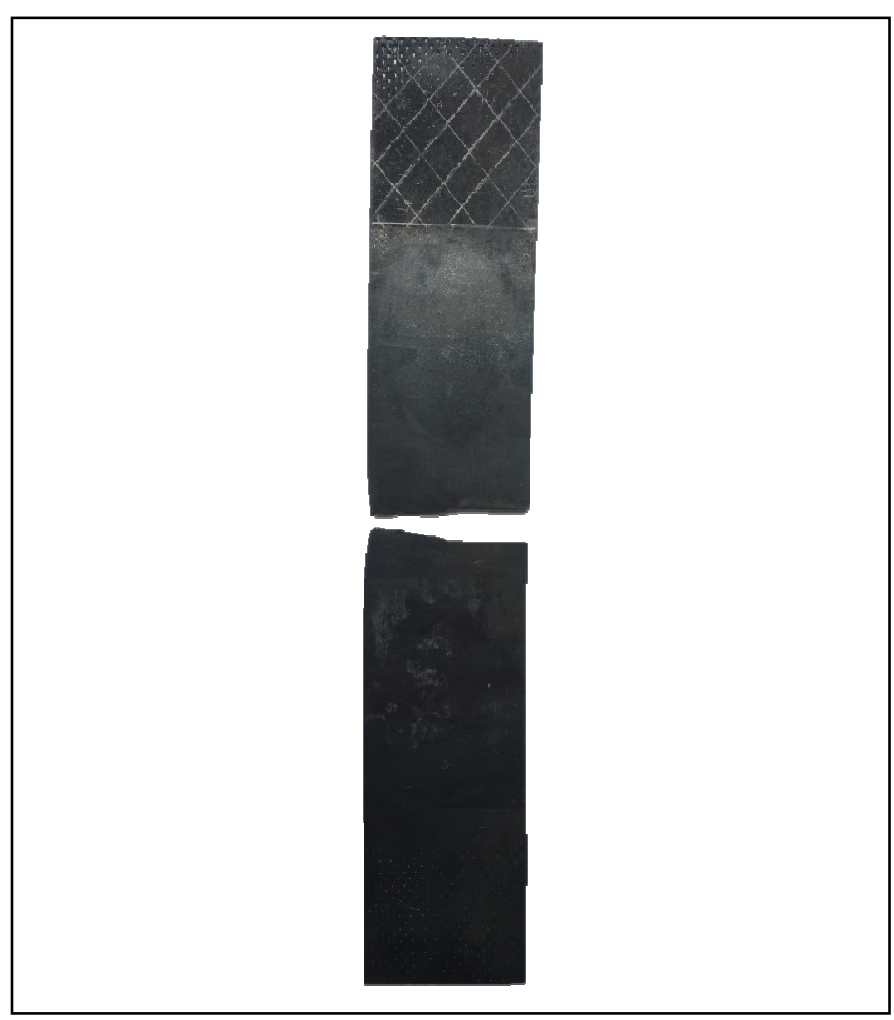

Fig. 11.09G2S steel sample after destruction

\section{DISCUSSION}

Analysis of the break nature shows that implementation of large plastic deformations was required to advance the fracture. As it is shown by experiments and stress design analysis in the fracture area [11,12], the real critical fracture size, which may increase, can be quite large. Since stresses at the fracture tip exceed the yield strength, the fracture can grow under nominal stresses realized in the elastic area. Singularity of stresses at the fracture tip reduces the accuracy of determining the critical stress coefficient $K_{I C}$ and, as a consequence, the accuracy of the critical fracture length determination. Therefore, a more reliable way of evaluation of the structural material fracture resistance is the use of the critical deformation intensity factor [13].

\section{CONCLUSION}

After analyzing the obtained results, one can make the following conclusions:
- Error of $\mathrm{K}_{\mathrm{I}}$ results obtained in the system of engineering analysis ANSYS MAPDL and by the analytical method (as per GOST) within the range of formula applicability $(\lambda \leq 0.6)$ is less than $1 \%$ and starts to grow when the fracture length exceeds $24 \mathrm{~mm}$. That corresponds to $\lambda=$ 0.6. In this connection, the authors can make the conclusion that it is practical and reasonable to solve problems of fracture mechanics in MAPDL.

- Difference of results, obtained in MAPDL and in WB, is almost constant and is less than $5 \%$. In this connection, the authors conclude that this error resulted from the difference in fracture geometry; thus, solving fracture mechanics problems in WB is also possible.

- For real structures, the obtained design factors should be used for calculation of deformation intensity factors.

\section{References}

[1] "On the industrial safety of hazardous production facilities (as amended on March 7. 2017) (edition came into force starting from March 25. 2017)," Federal Law of the Russian Federation № 116-FL. Art. 2.1.

[2] ASME B31G, "Manual for Determining the Remaining Strength of Corroded Pipelines."

[3] J.A. Collins, "Failure of materials in mechanical design," New York, 1981.

[4] M.F. Ashly, D.R.H. Jones, "Engineering Materials I: An Introduction to Properties. Applications and Design. Therd Edition," Pergamon Press, Oxford, 2005.

[5] R.R. Tlyasheva, V.A. Gafarova, K.R. Vagazova, A.M. Kuzeev, "Composition material for filling fracture cavity and fracture-like defects," Bashkir chemical journal, vol. 23, No. 3, p.p. 56-62, 2016.

[6] L. Xue, G.E.O. Widera, Z.F. Sang, "Influence of pad reinforcement on the limit and burst pressures of a cylinder-cylinder intersection," Journal of Pressure Vessel Technology, vol. 125, No. 2, p.p. 182-187, 2003.

[7] ANSYS Help. 2016 [electronic source] URL: https://www.sharcnet.ca/Software/Ansys/16.2.3/enus/help/ans_frac/.html (16.05.2017 г.).

[8] J. Rosler, H. Harders, M. Baker, "Mechanidchers Verhalten der Werkstoffe," Vieweg+Teubner. GWV Fachverlage GmbH. Wiesbadeb, 2008

[9] GOST 25.506-85, "Strength calculations and testing. Methods of metals mechanical testing. Determination of fracture resistance (fracture viscosity) characteristics under conditions of static loading," Interstate standard, 38 p, 1986.

[10] Y. Murakami, "Stress intensity factor handbook," The Society of Materials Science, vol. 2, Japan, 1987.

[11] R.S. Zaynullin, E.M. Morozov, A.A Aleksandrov, "Criteria of safe destruction of pipeline systems elements with fractures," Nauka, 2005, $316 \mathrm{p}$.

[12] A.A. Shaniavsky, "Safe fatigue destruction of airframe elements. Synergetics in engineering applications," Ufa, 2003, 803 p.

[13] N.A. Makhutov, "Structural strength, service life and anthropogenic safety: In 2 parts," Novosibirsk: Nauka, 2005. Part 1: Criteria of strength and service life, 494 p.; Part 2: Justification of service life and safety, $610 \mathrm{p}$. 